\title{
Gold Nanoparticle Paper-Based Dual-Detection Device for Forensics Applications
}

Wilson A. Ameku ${ }^{a}$, William R. de Araujo ${ }^{b}$,Clara J. Rangel ${ }^{a}$, Rômulo A. Ando ${ }^{a}$ and Thiago R. L. C. Paixão ${ }^{a^{*}}$

anstitute of Chemistry, University of São Paulo, São Paulo, SP 05508-000, Brazil

'Institute of Chemistry, Department of Analytical Chemistry, State University of Campinas UNICAMP, Campinas - SP, 13083-970, Brazil

*Corresponding author: trlcp@iq.usp.br

Phone: +551130919150. 

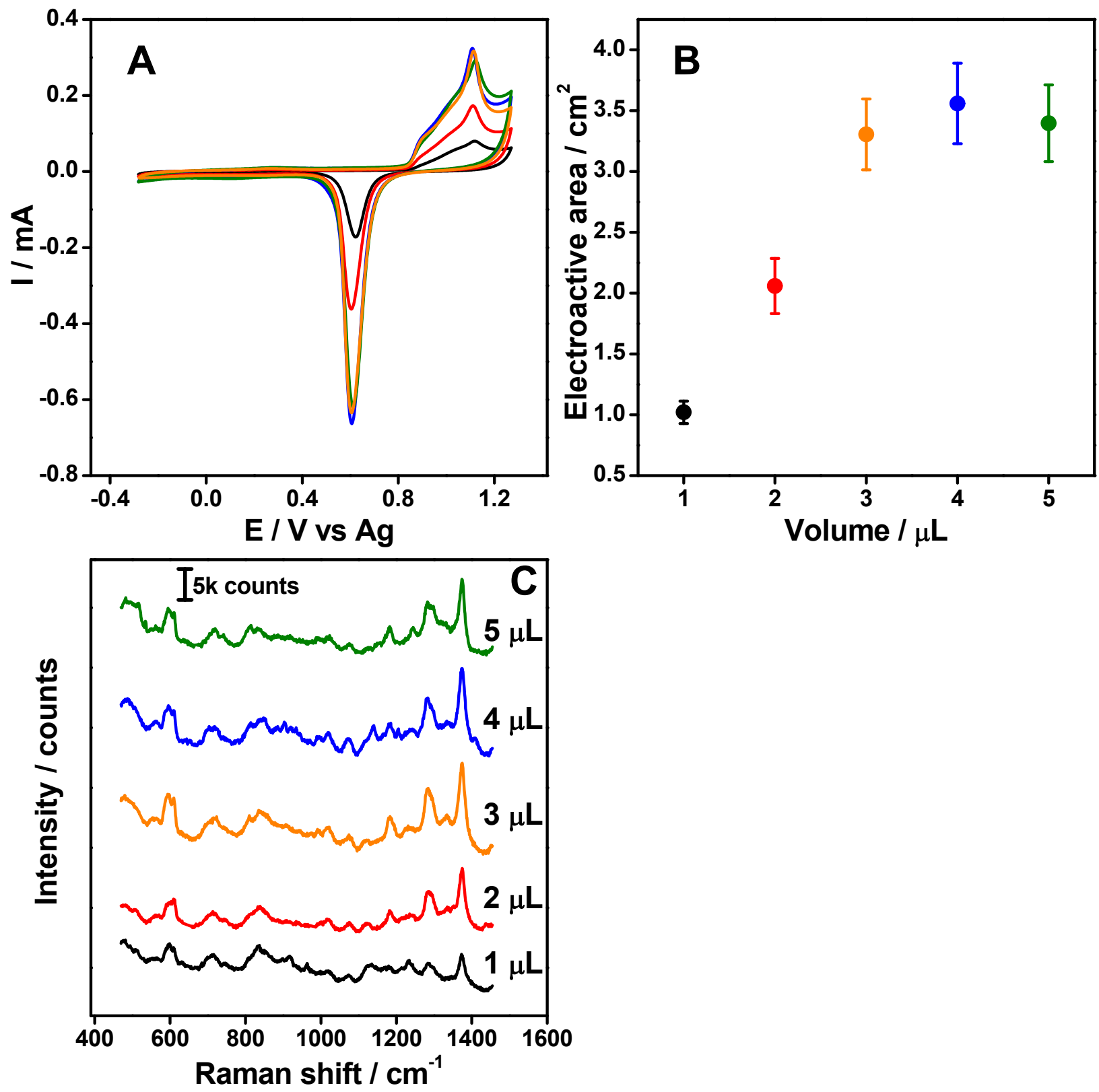

Figure S1 - The fabricating optimization process of the SERS-ePAD regarding different amount of AuNP suspension added on paper, $1 \mu \mathrm{L}$ (black line), $2 \mu \mathrm{L}$ (red line), $3 \mu \mathrm{L}$ (orange line), $4 \mu \mathrm{L}$ (blue line) and $5 \mu \mathrm{L}$ (green line). $\mathrm{CVs}$ recorded in $0.5 \mathrm{~mol} \mathrm{~L}^{-1} \mathrm{H}_{2} \mathrm{SO}_{4}$ solution with scan rate of 50 $\mathrm{mV} \mathrm{s}^{-1}$ using the SERS-ePADs prepared with different AuNP suspension volume (A). The graph shows the variance of calculated electroactive area of the fabricated devices in function of the AuNPs suspension volume (B). The SERS spectra obtained with $785 \mathrm{~nm}$ laser using $0.4 \mu \mathrm{mol} \mathrm{L}^{-}$ ${ }^{1}$ thiophene solution dropped on the gold region of the SERS-ePADs (C). 


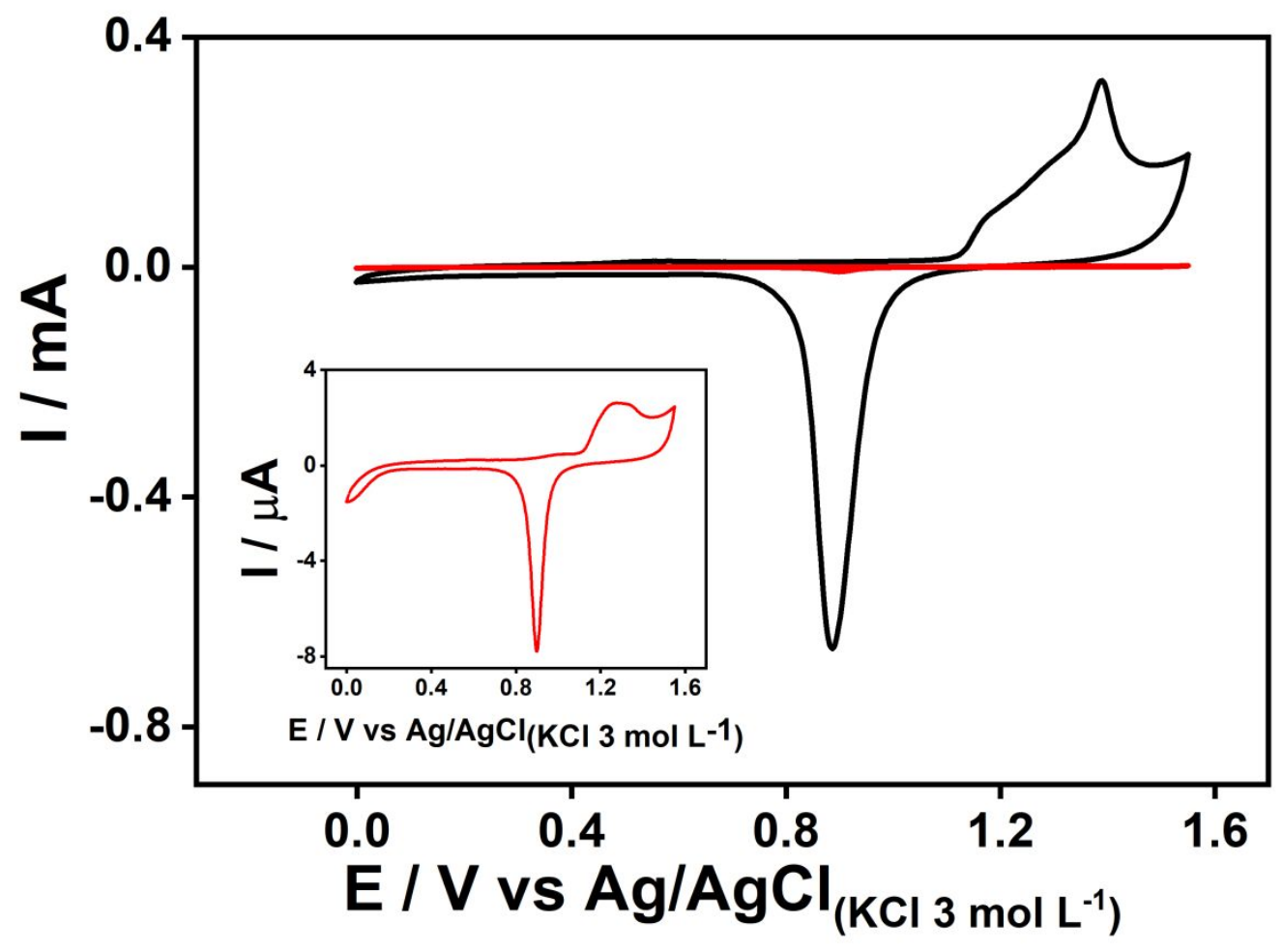

Figure $\mathrm{S} 2$ - CVs recorded in $0.5 \mathrm{~mol} \mathrm{~L}^{-1} \mathrm{H}_{2} \mathrm{SO}_{4}$ solution with a scan rate of $50 \mathrm{mV} \mathrm{s}^{-1}$ using SERSePAD (black line) and conventional Au electrode (red line) with the same geometric area as working electrode and $\mathrm{Ag} / \mathrm{AgCl}\left(\mathrm{KCl} 3 \mathrm{~mol} \mathrm{~L}^{-1}\right)$ as reference electrode. 


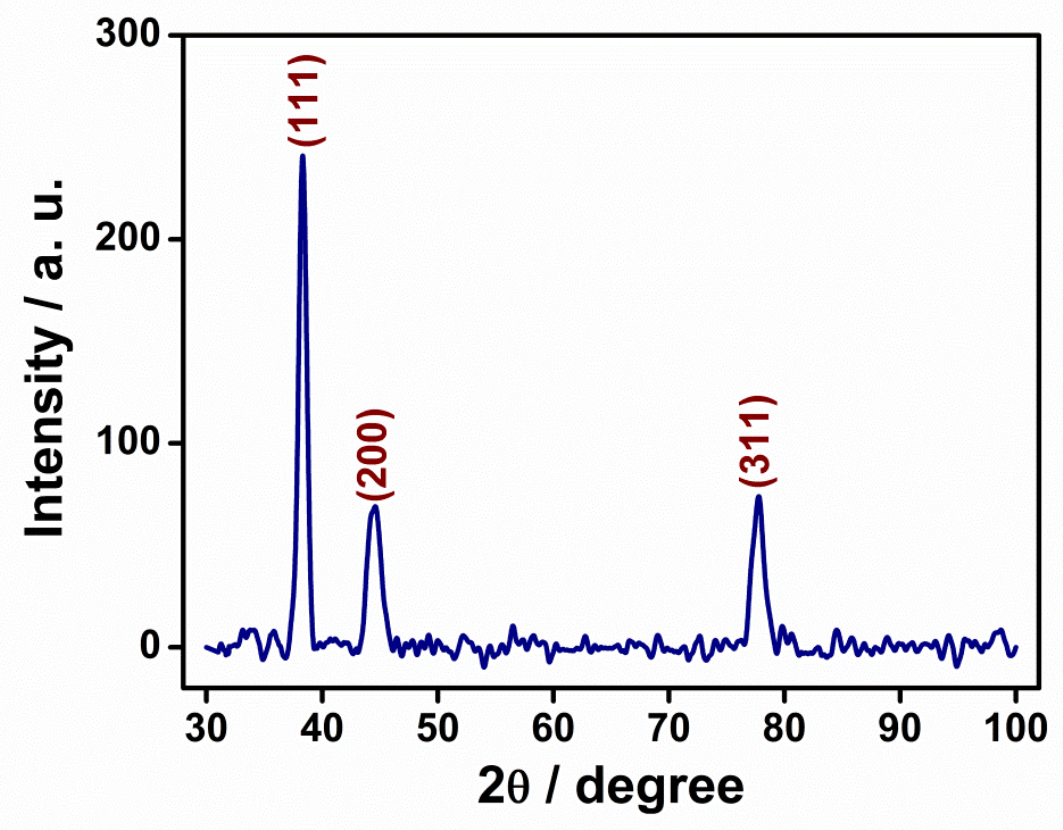

Figure S3 - XRD analysis of the SERS-ePAD device. The presented diffraction is a result of subtraction between office paper with wax barrier and SERS-ePAD (wax, office paper and AuNP film) XRDs.

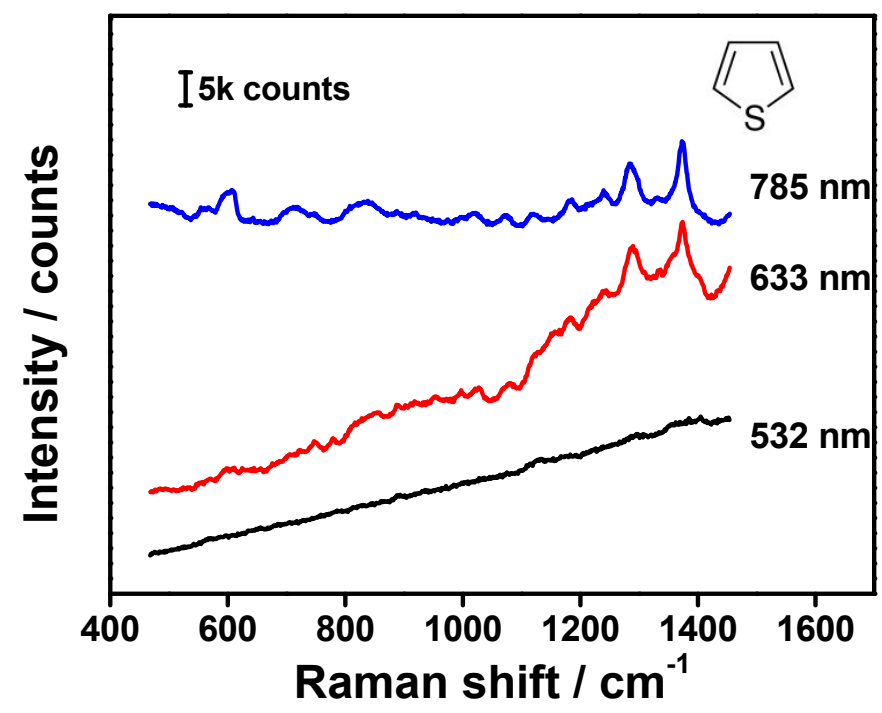

Figure S4 - SERS spectra of the $0.4 \mu \mathrm{mol} \mathrm{L}^{-1}$ thiophene solution acquired in the same SERSePAD device and using different excitation lights, i.e. 532,633 and $785 \mathrm{~nm}$ with power of 0.71 , 0.43 and $0.27 \mathrm{~mW}$, respectively. 


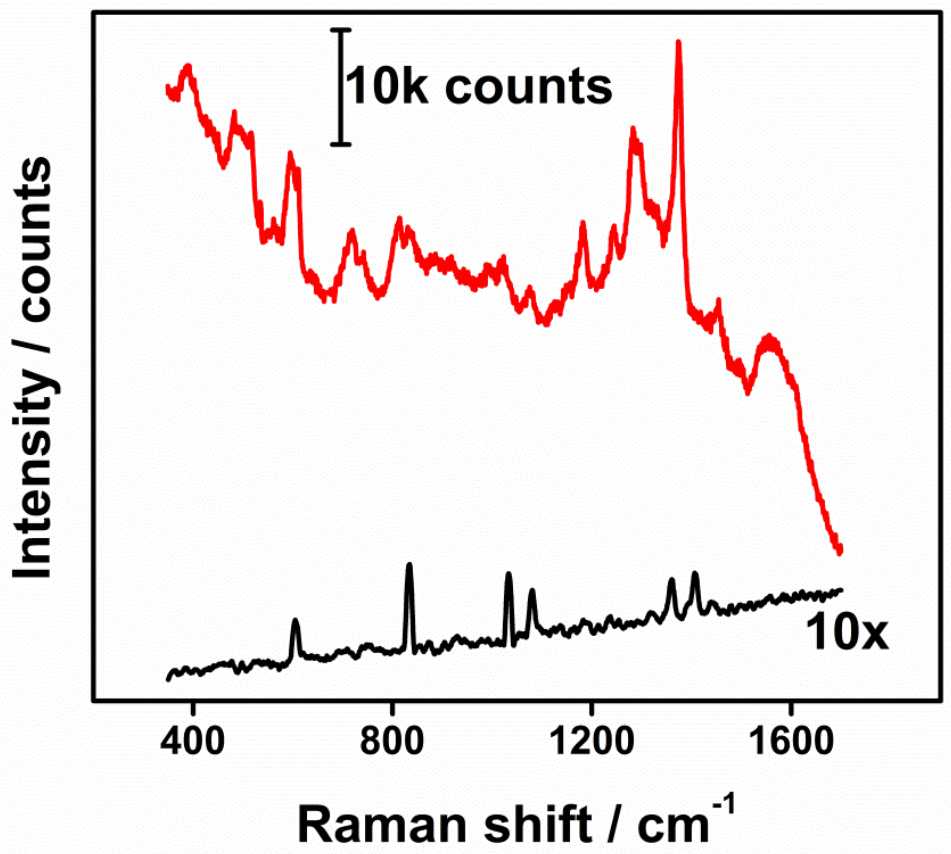

Figure S5: SERS spectrum of the $0.4 \mu \mathrm{mol} \mathrm{L} \mathrm{L}^{-1}$ thiophene solution using SERS-ePAD (red line) and conventional Raman spectrum of the pure liquid of thiophene (12 mol L-1) (black line), both spectra was registered using $785 \mathrm{~nm}$-excitation light with power of $0.27 \mathrm{~mW}$.

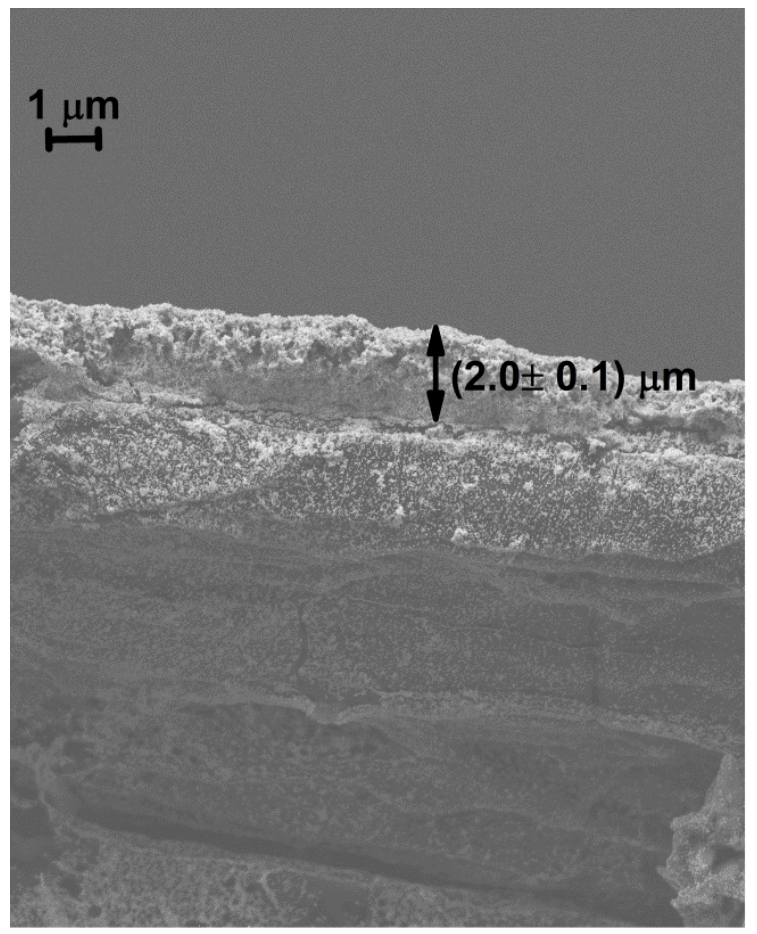

Figure S6 - SEM cross-section micrograph of the SERS-ePAD device. 


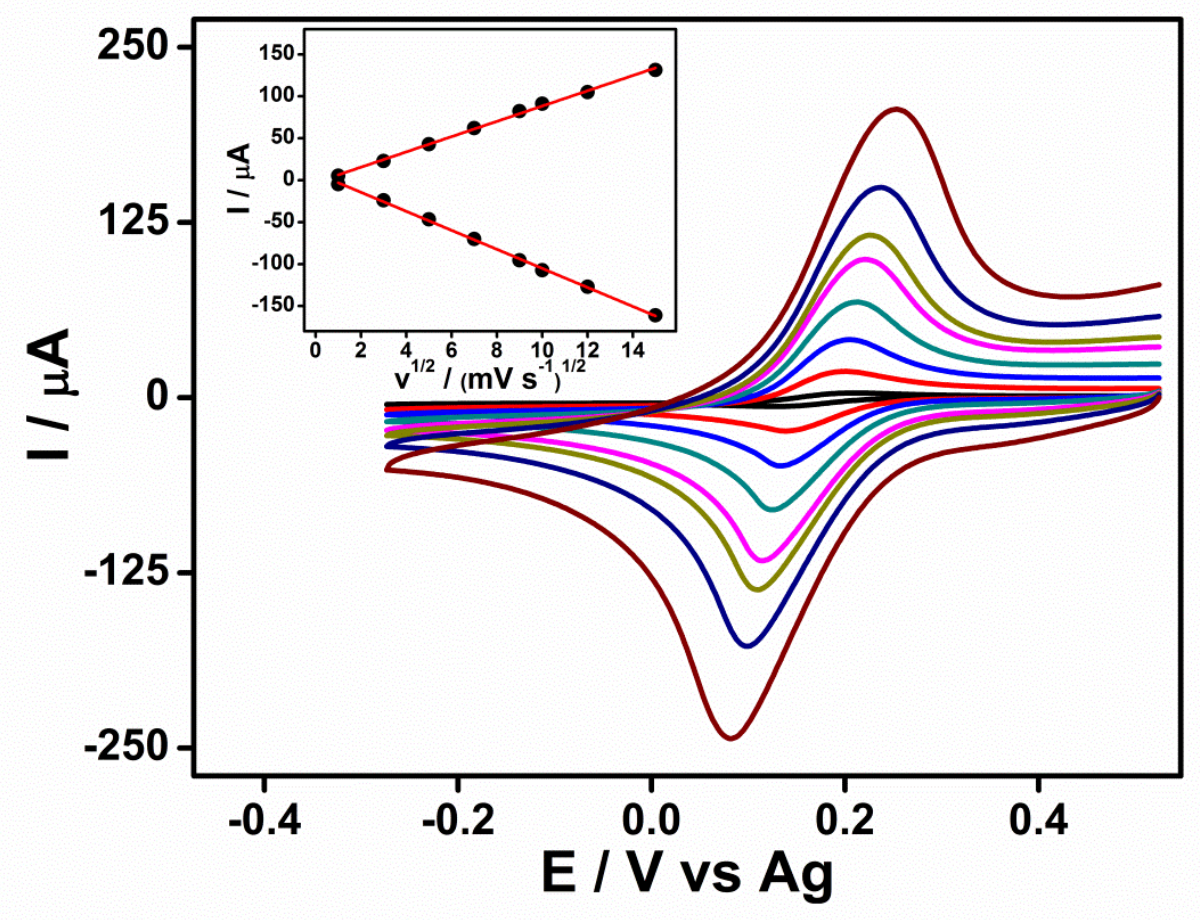

Figure $\mathrm{S} 7$ - CVs obtained in $0.10 \mathrm{~mol} \mathrm{~L}^{-1} \mathrm{KCl}$ solution containing $7 \mathrm{mmol} \mathrm{L}^{-1}\left[\mathrm{Fe}(\mathrm{CN})_{6}\right]^{-3}$ for scan rate ranging from $1 \mathrm{mV} \mathrm{s}^{-1}$ to $225 \mathrm{mV} \mathrm{s}^{-1}$. Inset the plot of anodic and cathodic peaks in function of square root of scan rate values.

As shown in the inset of Fig. S7, both anodic and cathodic peak intensities presented linear behavior with the square root of the scan rate, demonstrating that the electrochemical process was controlled by diffusion. It is worth noting that the CVs exhibited similar current intensities for both anodic and cathodic processes evidencing that its reversible nature was maintained. 


\section{$\underline{\text { Reproducibility tests }}$}

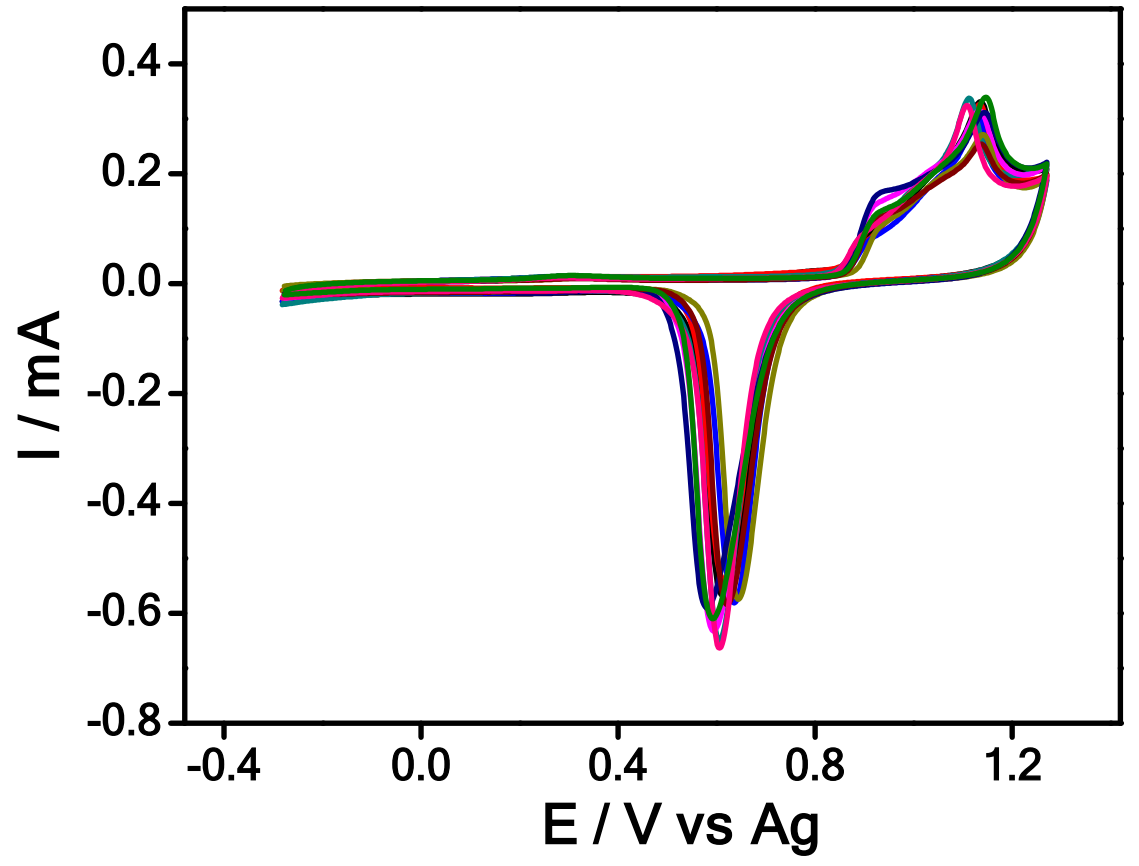

Figure S8 - Reproducibility assay for CV recorded in $0.5 \mathrm{~mol} \mathrm{~L}^{-1} \mathrm{H}_{2} \mathrm{SO}_{4}$ solution using 10 different SERS-ePAD devices. The RSD of the electrodes were $8.8 \%$. 


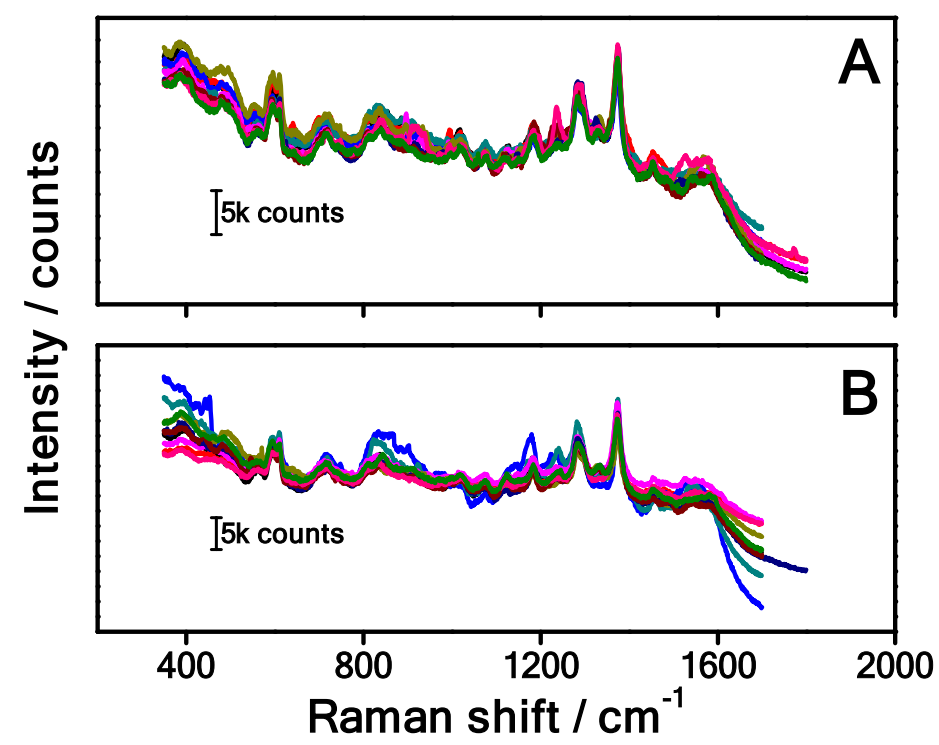

Figure S9 - Repeatability assays for SERS signals using $0.4 \mu \mathrm{mol} \mathrm{L} \mathrm{L}^{-1}$ thiophene solution, it was considered its $1375 \mathrm{~cm}^{-1}$ band variation in different points in one SERS-ePAD device (A) and in one point in ten different SERS-ePAD devices (B) where the RSD were $11.3 \%$ and $13.1 \%$, respectively. 

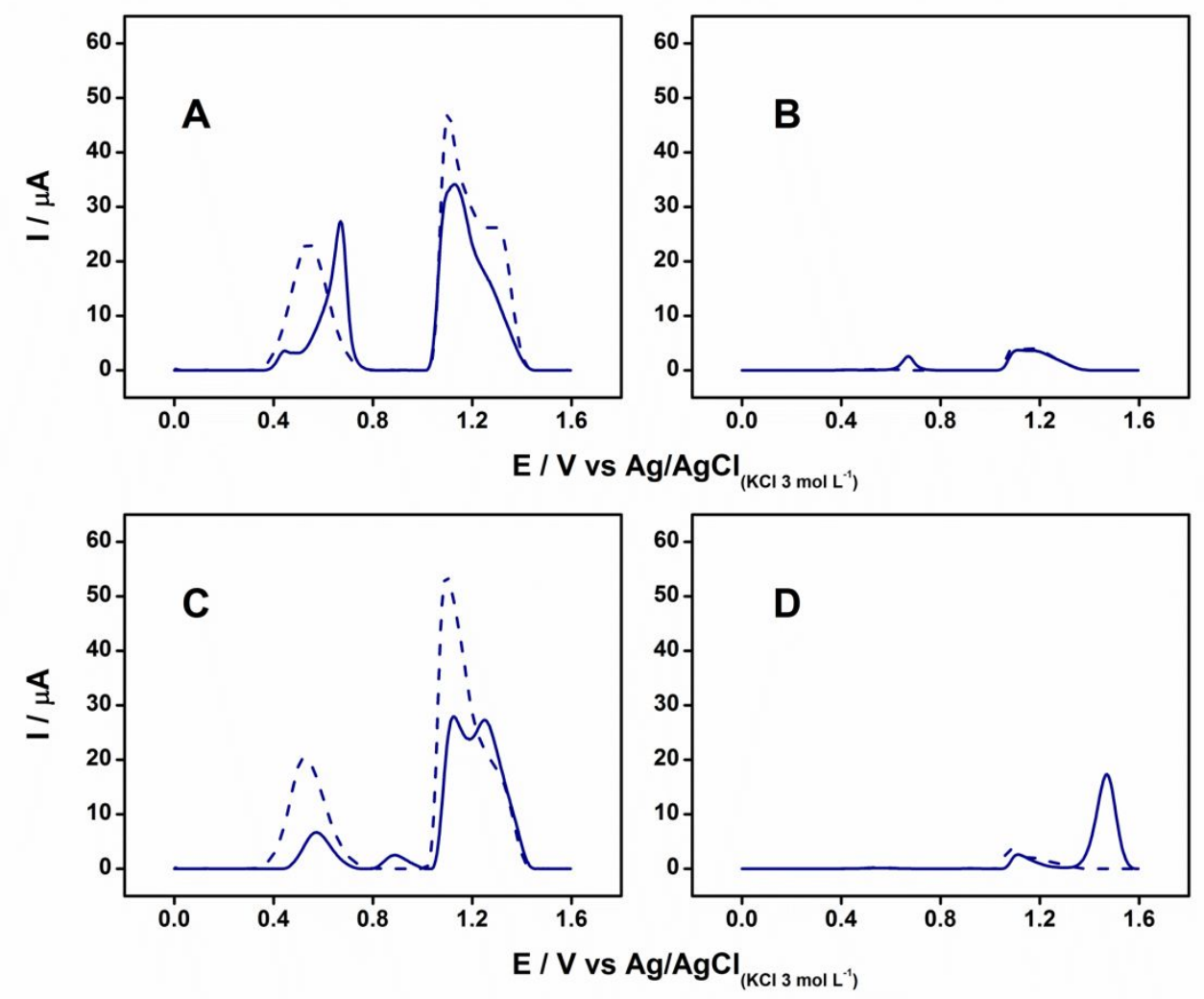

Figure S10 - DPVs obtained at scan rate of $10 \mathrm{mV} \mathrm{s}^{-1}$, step of $5 \mathrm{mV}$, amplitude of $40 \mathrm{mV}$, modulation time of $0.10 \mathrm{~s}$ and interval time of $0.50 \mathrm{~s}$ in $0.05 \mathrm{~mol} \mathrm{~L}^{-1} \mathrm{H}_{2} \mathrm{SO}_{4}$ solution (dash line) with $5 \mathrm{mmol} \mathrm{L}^{-1}$ and $300 \mu \mathrm{mol} \mathrm{L}-1$ standard solution of PAR (A and B) and CAF (C and D), respectively (solid line) using SERS-ePAD (A and C) and conventional Au electrode (B and D) as working electrode, both of them presented same geometrical area and $\mathrm{Ag} / \mathrm{AgCl}(\mathrm{KCl} 3 \mathrm{~mol}$ $\left.\mathrm{L}^{-1}\right)$ as reference electrode. 

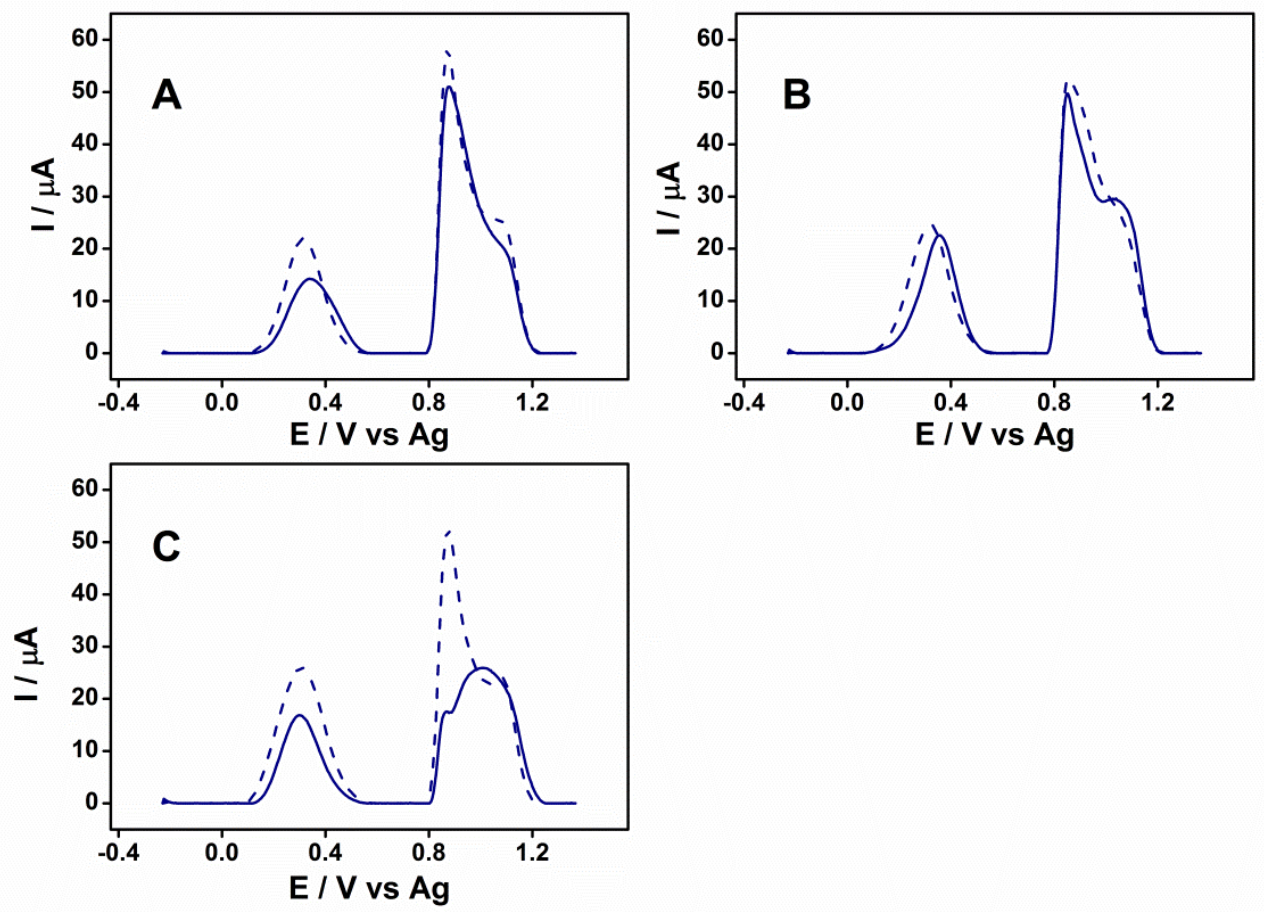

Figure S11 - DPVs obtained at scan rate of $10 \mathrm{mV} \mathrm{s}^{-1}$, step of $5 \mathrm{mV}$, amplitude of $40 \mathrm{mV}$, modulation time of $0.1 \mathrm{~s}$ and interval time of $0.5 \mathrm{~s}$ in $0.05 \mathrm{~mol} \mathrm{~L}^{-1} \mathrm{H}_{2} \mathrm{SO}_{4}$ solution (dash line) using SERS-ePAD with $0.5 \mathrm{mmol} \mathrm{L}^{-1}$ standard solution of LID (A), COC (B) and LEV (C) (solid line). 


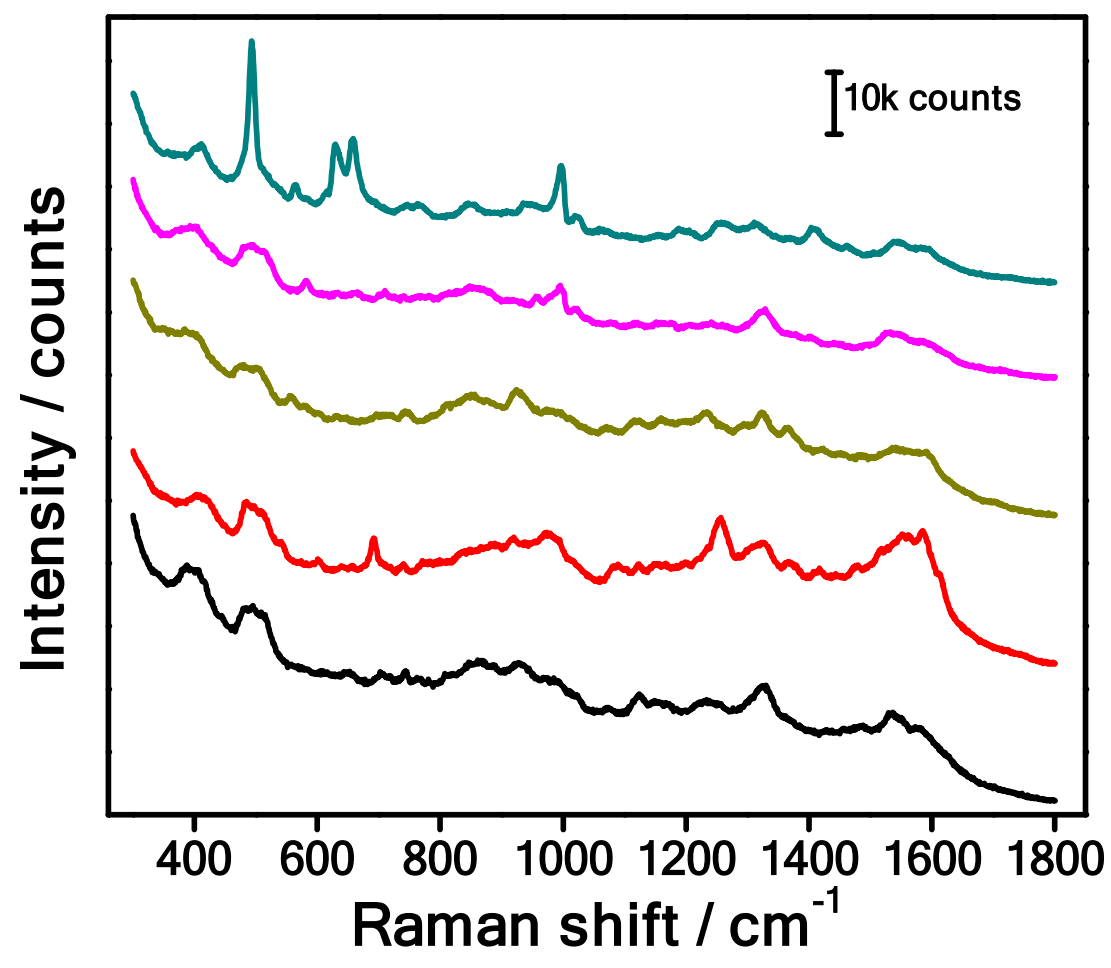

Figure S12 - SERS spectra obtained with laser wavelength of $785 \mathrm{~nm}$ from the aqueous media (black line) and $100 \mu \mathrm{mol} \mathrm{L}^{-1}$ standard aqueous solution of LID (red), CAF (dark yellow), COC (magenta) and LEV (dark cyan). 